\title{
Quantitative analysis and health risk assessment of methanol in medicinal herbal drinks marketed in Hamadan, Iran
}

\author{
Amir Nili-Ahmadabadi ${ }^{1 *}$, Mahsa Sedaghat ${ }^{2}$, Akram Ranjbar $^{1}$, Jalal Poorolajal ${ }^{3}$, Hamid Nasiripour ${ }^{4}$, Maryam Nili- \\ Ahmadabadi ${ }^{5}$ \\ ${ }^{1}$ Department of Pharmacology and Toxicology, Faculty of Pharmacy, Hamadan University of Medical Sciences, Hamadan, Iran. ${ }^{2}$ Department of \\ Pharmacognosy, Faculty of Pharmacy, Hamadan University of Medical Sciences, Hamadan, Iran. ${ }^{3}$ Research Center for Modeling of No Communicable \\ Diseases, School of Public Health, Hamadan University of Medical Sciences, Hamadan, Iran. ${ }^{4}$ Department of Toxicology, Faculty of Pharmacy, Islamic \\ Azad University, Shahreza Branch, Shahreza, Iran. ${ }^{5}$ Department of Pharmaceutical Chemistry, School of Pharmacy, Shahid Beheshti University of Medical \\ Sciences, Tehran, Iran.
}

\section{ARTICLE INFO}

Article history:

Received on: 24/02/2016

Revised on: $15 / 03 / 2016$

Accepted on: 22/04/2016

Available online: 28/07/2016

Key words:

Methanol, Herbal drinks, Gas

chromatography, Iran.

\begin{abstract}
Herbal drinks are one of the most important and widely used pharmaceutical forms of medicinal herbs. Methanol, a neurotoxic agent, occurs naturally at different levels during the production of herbal drinks. The aim of this study was to evaluate contamination and dietary intake of methanol by herbal drinks consumption in Hamadan, Iran. In current study, sixty samples from five types of herbal drinks were analyzed for methanol and ethanol by gas chromatography. The results showed that thirty-three samples were positive for methanol at levels that ranged from 8.35 to $31.90 \mathrm{mg} / \mathrm{dl}$. Additionally, in the positive samples, the ratio of methanol/ ethanol was greater than the European Union acceptable limit. Although methanol intake was estimated within acceptable limits, some of the Iranian consumers might need to moderate their herbal drinks consumption.
\end{abstract}

\section{INTRODUCTION}

The World Health Organization (WHO) has reported that about $80 \%$ of the people in developing countries depend on traditional medicine for their health needs (Nili-Ahmadabadi et al., 2011). Herbal extracts, are one of the most important, effective, and widely used pharmaceutical forms of medicinal herbs (Delfan et al., 2014). The Iranian National Standards Institute defines herbal extracts as aromatic distilled waters and saturated aqueous solutions of volatile plant oils or other aromatic substances obtained from fresh or dried plant organs (Namdari et al., 2014). In addition to medical applications, herbal extracts are used as dietary supplements in food industries

* Corresponding Author

Dr. Amir Nili-Ahmadabadi, Mail id;amirnili54@gmail.com; Department of Pharmacology and Toxicology, Faculty of Pharmacy, Hamadan University of Medical Sciences, Hamadan, Iran. P.O. Box 8678-3-65178, Tel/Fax:+988138380031.
(Mousavi et al., 2010). In recent years, drinks derived from herbal extracts are commonly used in Iran and other countries. Methanol, a neurotoxic agent (Reddy et al., 2010; Jahan et al., 2015), occurs naturally at different levels during the production of herbal drinks (Mousavi et al., 2010) and alcoholic beverages (Lachenmeier et al., 2008; Croitoru et al., 2013). Methanol toxicity is mediated primarily by formaldehyde and formate, its primary metabolites (Jahan et al., 2015). Formate is metabolized through combination with tetrahydrofolate to produce 10 -formyl tetrahydrofolate. This product finally undergoes conversion to water and carbon dioxide (Rachelle and Watterson, 2008). Therefore, the folate storage could be associated with severity of methanol toxicity. The methanol contamination in herbal drinks is a result of demethylation of cell wall pectins by pectin methylesterase, which improves tissue firmness (Mousavi et al., 2010). Previous studies have shown that immersion of thin pieces of vegetable tissue and heating to activate pectin methylesterase results in a rapid increase in methanol in the bathing solution (Anthon and Barrett, 2006). 
Acute methanol toxicity leads to a high-anion-gap metabolic acidosis with an elevated osmolal gap, renal failure, blindness, and even death (Beno et al., 2011). Frequent consumption of some herbal drinks may therefore induce severe damage, particularly blindness (Mousavi et al., 2010). By contrast, chronic methanol toxicity is not well characterized, although recent data have indicated that increases in endogenous levels of formaldehyde due to metabolism of endogenous methanol could be a possible marker for progressive senile dementia (Tong et al., 2011). Shindyapina et al. (2014) have also shown that dietary methanol and increases in formaldehyde concentrations in the blood plasma can change the expression of genes involved in the pathogenesis of Alzheimer's disease. Methanol intake due to consumption of herbal drinks could be more important than intake from consumption of alcoholic beverages because the ethanol in alcoholic beverages can antagonize the methanol effects in biological systems. In the present study we aimed to evaluate the intake of methanol by herbal drinks consumption in Hamadan, Iran during the period of October 2014 to March 2015.

\section{METHODS AND MATERIALS}

\section{Samples}

Sixty samples of five types of commonly-used herbal drinks available in Hamadan, Iran, were purchased from local markets during the period of October 2014 to March 2015. All samples were kept under suitable conditions and were analyzed as soon as possible.

\section{Apparatus and reagents}

Methanol and ethanol in the herbal drinks samples were quantitatively analyzed with a gas chromatograph (GC) (Agilent 6850, USA) equipped with a flame ionization detector (FID), a splitless injector, a matrix 80/100 Porapak Q column [0.91 m (L) x $1.8 \mathrm{~mm}$ (O.D) x $2 \mathrm{~mm}$ (I.D), stainless steel]. Ethanol and methanol with a purity of $99 \%$ (GC grade) were purchased from Merck (Darmstadt, Germany).

\section{Sample preparation}

The samples $(0.4 \mathrm{~mL})$ were diluted with deionized water into $100 \mathrm{ml}$ volumetric flasks. After $3 \mathrm{~min}$ of vortex shaking, $2 \mu \mathrm{l}$ samples were injected into the GC equipment.

\section{Chromatographic conditions}

The carrier gas was nitrogen. The oven temperature was programmed at $50^{\circ} \mathrm{C}$ for 2 minutes and increased to $140^{\circ} \mathrm{C}$ for 6 minutes. The injector temperature was set at $160^{\circ} \mathrm{C}$, the detector temperature was $220^{\circ} \mathrm{C}$; and the gas flow was $30 \mathrm{~mL} / \mathrm{min}$. Retention times for methanol and ethanol were 1.7, and $4.4 \mathrm{~min}$, respectively.

\section{Calibration curve}

Calibration curves for ethanol and methanol were constructed using external standards in a range from 5 to $50 \mathrm{mg} / \mathrm{dl}$, prepared by dilution of a stock solution in deionized water. The limits of detection (LOD) and limits of quantification (LOQ) were determined as $\mathrm{S} / \mathrm{N}=3$ and $\mathrm{S} / \mathrm{N}=9$, respectively, where $\mathrm{S} / \mathrm{N}$ is the ratio of signal/noise in a spiked matrix.

\section{Quality assurance}

The reliability of the results of the alcohol analysis was assessed by conducting internal quality control experiments, in addition to using validated methods. In this regard, recoveries of alcohols were recorded by analyzing an herbal drink sample spiked with certain concentrations $(5,15$ and $30 \mathrm{mg} / \mathrm{dl})$ of either methanol or ethanol.

\section{Health risk assessment}

Daily intake of methanol (DIM) was calculated using the following equation: $(\mathrm{DIM})=\mathrm{CM} \times \mathrm{DI} / \mathrm{BW}$.

In this equation, $\mathrm{CM}, \mathrm{DI}$ and $\mathrm{BW}$ represent the methanol level in herbal drinks (mg/dl), daily intake of herbal drinks and average body weight, respectively. It should be noted that the average of body weight and herbal drinks consumption were assumed $60 \mathrm{~kg}$ and $10 \mathrm{ml} / \mathrm{day}$, respectively.

The Health Risk Index (HRI) was determined as the ratio of estimated methanol exposure through consumption of herbal drinks in Iranian population. According to the data in Integrated Risk Information System (IRIS), an oral reference dose (RfD) for methanol is $2 \mathrm{mg} / \mathrm{kg} /$ day (US. EPA, 2010). Therefore, The HRI was calculated by the formula DIM/RfD. HRI of more than 1 was considered unsafe for human health.

\section{Statistical analysis}

The results were expressed as mean $\pm \mathrm{SD}$ and analyzed using SPSS software version 11.5 through one-way analysis of variance (ANOVA). The $\mathrm{P}<0.05$ was considered statistically significant.

\section{RESULTS}

The standard curve data for methanol and ethanol detection using a gas chromatography system are given in Table 1. The $r^{2}$ indexes indicated an acceptable calibration curve, which was linear in the $5-50 \mathrm{mg} / \mathrm{dl}$ range. Also, the calculated LOD and LOQ values suggested a good performance at low statutory limits. As shown in Table 2, the RSD values of the recovery test were within the acceptable ranges, indicating the good accuracy and precision of this analytical method. In the present study, methanol was detected in $33(55 \%)$ samples, at levels ranging from 8.35 to $31.90 \mathrm{mg} / \mathrm{dl}$. The mean methanol concentration was $16.92 \pm 7.24$ $\mathrm{mg} / \mathrm{dl}$ in contaminated samples. No significant difference was observed in the methanol levels among different herbal drinks. Ethanol was only seen in $8(13.3 \%)$ of the samples, with an overall mean content of $51.63 \pm 29.56 \mathrm{mg} / \mathrm{dl}$ (Note that ethanol was not detected in herbal distillates except those from Rosa damascena). The methanol and ethanol contents in different herbal drinks are presented in Table 3. 
Table 1: Linearity range and detection limits for GC-FID analyses.

\begin{tabular}{|c|c|c|c|c|c|}
\hline Alcohols & Range & Linear equation & $\mathbf{R}^{2}$ & LOD (mg/dl) & LOQ (mg/dl) \\
\hline Methanol & $5-50$ & $Y=114.43 x+7.3415$ & 0.9999 & 0.74 & 2.46 \\
\hline Ethanol & $5-50$ & $Y=146.72 x-1.0966$ & 0.9999 & 0.52 & 1.73 \\
\hline
\end{tabular}

Table 2: Recoveries of methanol and ethanol in spiked herbal drinks samples.

\begin{tabular}{|c|c|c|c|c|}
\hline Alcohol spiked & Alcohol spiked (mg/dl) & Alcohol found (mg/dl) & Recovery $(\%)$ & $\operatorname{RSD}(\%)^{\dagger}$ \\
\hline \multirow{3}{*}{ Methanol } & 5 & 4.43 & 88.6 & 7.8 \\
\hline & 15 & 13.35 & 89 & 5.3 \\
\hline & 30 & 28.86 & 96.2 & 3.4 \\
\hline \multirow{3}{*}{ Ethanol } & 5 & 4.64 & 92.8 & 7.7 \\
\hline & 15 & 14.52 & 96.8 & 5.8 \\
\hline & 30 & 31.20 & 104 & 4.8 \\
\hline
\end{tabular}

${ }^{\dagger}$ Relative standard deviation (RSD) was obtained from triplicate tests.

Table 3: Methanol and ethanol contents detected in herbal drinks samples.

\begin{tabular}{|c|c|c|c|c|c|c|c|c|}
\hline \multirow[t]{2}{*}{ Herbal distillates } & \multicolumn{4}{|c|}{ Methanol (mg/dl) } & \multicolumn{4}{|c|}{ Ethanol (mg/dl) } \\
\hline & Mean & SD & Max & Min & Mean & SD & Max & Min \\
\hline Anethum graveolens & 17.36 & 8.22 & 30.24 & 9.55 & $\mathrm{ND}^{\dagger}$ & ND & ND & ND \\
\hline Cichorium intybus & 20.08 & 9.11 & 31.90 & 8.38 & ND & ND & ND & ND \\
\hline Rosa damascena & 16.33 & 6.73 & 26.94 & 9.71 & 51.63 & 29.56 & 87.38 & 9.35 \\
\hline Mentha longifolia & 15.23 & 4.81 & 21.50 & 8.39 & ND & ND & ND & ND \\
\hline Salix aegyptiaca & 16.03 & 8.87 & 31.44 & 8.35 & ND & ND & ND & ND \\
\hline
\end{tabular}

${ }^{\dagger}$ Not detected.

Table 4: Daily intake and Health Risk Indexes of methanol through consumption of herbal drinks.

\begin{tabular}{|c|c|c|c|c|c|c|}
\hline \multirow{2}{*}{ Herbal distillates } & \multicolumn{3}{|c|}{ Daily intake (mg/kg body weight) } & \multicolumn{3}{|c|}{ Health Risk Indexes (HRI) } \\
\hline & Mean & Max & Min & Mean & Max & Min \\
\hline Anethum graveolens & 0.030 & 0.050 & 0.016 & 0.014 & 0.025 & 0.008 \\
\hline Cichorium intybus & 0.033 & 0.053 & 0.014 & 0.016 & 0.026 & 0.007 \\
\hline Rosa damascena & 0.027 & 0.045 & 0.016 & 0.013 & 0.022 & 0.008 \\
\hline Mentha longifolia & 0.025 & 0.035 & 0.014 & 0.012 & 0.017 & 0.007 \\
\hline Salix aegyptiaca & 0.026 & 0.052 & 0.014 & 0.013 & 0.026 & 0.007 \\
\hline
\end{tabular}

\section{DISCUSSION}

In this study, occurrence of methanol contamination in herbal drinks was confirmed in Hamadan, Iran. Our findings are comparable to those published in other reports. For instance, Karimi et al. (2007) determined that the methanol contamination in 10 different types of herbal drinks ranged from 7.94 to 144.70 $\mathrm{mg} / \mathrm{dl}$. A study conducted in Urmia in 2012, which examined six different types of herbal drinks for methanol, detected concentrations that ranged from 7.24 to $27.83 \mathrm{mg} / \mathrm{dl}$ (Delirrad et al., 2012). These wide variations in methanol contamination among different studies could be related to the pectin content and pectin methylesterase activity in various plants and also to differences in the processes used in the production of the herbal drinks (Mousavi et al., 2010; Anthon and Barrett, 2006).

The permissible limits for methanol in herbal drinks or other non-alcoholic beverages have not yet been defined, although the European Union (EU) accepts a naturally occurring methanol content of $10 \mathrm{~g}$ methanol/L ethanol in alcoholic beverages. This equates to $0.4 \%(\mathrm{v} / \mathrm{v})$ methanol in an alcoholic drink containing 40\% alcohol (Paine and Davan, 2001; Croitoru et al., 2013). Therefore, the acceptable intake of methanol is higher in alcoholic than in non-alcoholic beverages because ethanol is present in alcoholic beverages. In the present study, the ratio of methanol/ ethanol was more than EU acceptable limit. However, even if methanol damage is far less in the presence of ethanol, the chronic use of these products could be considered a health risk.
To evaluate the rate of the risk, DIM and HRI indexes were calculated based on methanol levels in various herbal drinks (Table 4). The results were demonstrated that the methanol level in these products can be considered safe in normal persons if the herbal drink consumption was assumed $10 \mathrm{ml} /$ daily. However, pregnant women, alcoholic patients, and/or elderly persons are especially can be exposed to this risk due to folate deficiency (Croitoru et al., 2013). Thus, these persons as well as people who use herbal drinks more than $375 \mathrm{ml} /$ daily might need to moderate these drinks consumption.

\section{CONCLUSION}

Taken collectively, our findings confirmed the occurrence of methanol contamination in more than half of the herbal drinks collected in Hamadan, Iran. The existing evidence indicates that the risk of methanol exposure may be considerable for high risk populations due to consumption of certain kinds of herbal drinks. Therefore, efforts should be taken to increase the quality of these drinks by improving the production processes. Standardization of these products is also recommended.

\section{ACKNOWLEDGMENT}

The study protocol was approved in the institute review board with code number of (9211304111) and supported by Hamadan University of Medical Sciences, Hamadan, Iran. 


\section{CONFLICT OF INTEREST}

The authors declare that there is no conflict of interest.

\section{REFERENCES}

Anthon GE, Barrett DM. Characterization of the temperature activation of pectin methylesterase in green beans and tomatoes. J Agric Food Chem, 2006; 54: 204-211.

Beno JM, Hartman R, Wallace C, Nemeth D, LaPoint S. Homicidal methanol poisoning in a child. J Anal Toxicol, 2011; 35: 524528.

Croitoru MD, Elena T, Ibolya F, Erzsébet F. A Survey on the Methanol Content of Home Distilled Alcoholic Beverages in Transylvania (Romania). Acta Medica Marisiensis, 2013; 59: 206-208.

Delfan B, Bahmani M, Rafieian-Kopaei M, Delfan M, Saki K. A review study on ethnobotanical study of medicinal plants used in relief of toothache in Lorestan Province, Iran. Asian Pac J Trop Dis, 2014; 4: 879-884.

Delirrad M, Ghasempour Z, Hassanzadazar H, Roshani Y, Mohammadi M, Forouzan S, Rahimirad A, Hamzehzadeh A. Determination of methanol content in herbal distillates produced in Urmia using spectrophotometry. Iranian Journal of Toxicology, 2012; 6: 594-599.

Jahan K, Mahmood D, Fahim M. Effects of methanol in blood pressure and heart rate in the rat. J Pharm Bioallied Sci, 2015; 7: 60-64.

Karimi G, Hasanzadeh M, Shahidi N, Samiei Z. Quantitative determination of methanol in plant water produced in Mashhad by spectrophotometry method. J Med Plants, 2008; 1: 56-59.

Lachenmeier DW, Haupt S, Schulz K. Defining maximum levels of higher alcohols in alcoholic beverages and surrogate alcohol products. Regul Toxicol Pharmcol, 2008; 50: 313-321.

Mousavi SR, Namaei-Ghassemi M, Layegh M, Afzal-Aghaee M, Vafaee M, Gholamali Zare G, Moghiman T, Balali Mood M. Determination of methanol concentrations in traditional herbal waters of different brands in Iran. Iran. J Basic Med Sci, 2011; 14: 361-368.
Namdari F, Eghbali B, Bahmani M, Rafieian-Kopaei M, Hassanzadazar H, Moghimi-Monfared O, Ghazi N, Sharifi A. A survey on microbial quality of herbal distillates in Isfahan, central of Iran. Studia Univ VG, SSV, 2014; 24: 407-414.

Nili-Ahmadabadi A, Tavakoli F, Hasanzadeh GR, Rahimi HR, Sabzevari O. Protective effect of pretreatment with thymoquinone against Aflatoxin B1 induced liver toxicity in mice. Daru, 2011; 19: 282-287.

Paine A, Davan AD. Defining a tolerable concentration of methanol in alcoholic drinks. Hum Exp Toxicol, 2001; 20: 563-568.

Rachelle WH, Watterson JH. Formic acid and methanol concentrations in death investigations. J Anal Toxicol, 2008; 32: 241-247.

Reddy NJ, Sudini M, Lewis LD. Delayed neurological sequelae from ethylene glycol, diethylene glycol and methanol poisonings. Clin Toxicol Phila, 2010; 48: 967-973.

Shindyapina AV, Petrunia IV, Komarova TV, Sheshukova EV, Kosorukov VS, Kiryanov GI, Dorokhov YL. Dietary methanol regulates human gene activity. PloS one, 2014; 9: 1-16.

Tong Z, Zhang J, Luo W, Wang W, Li F, Li H, Luo H, Lu J, Zhou J, Wan Y, He R. Urine formaldehyde level is inversely correlated to mini mental state examination scores in senile dementia. Neurobiol Aging, 2011; 32: 31-41.

U.S. EPA. IRIS Toxicological Review of Methanol (External Review Draft; December 2009). U.S. Environmental Protection Agency, Washington, DC, EPA/635/R-09/013, 2010.

\section{How to cite this article:}

Ahmadabadi AN, Sedaghat M, Ranjbar A, Poorolajal J, Nasiripour $\mathrm{H}$, Ahmadabadi MN. Quantitative analysis and health risk assessment of methanol in medicinal herbal drinks marketed in Hamadan, Iran. J App Pharm Sci, 2016; 6 (07): 049-052. 